\title{
Measuring urban sustainability and liveability performance: the City Analysis Methodology
}

\author{
Joanne M. Leach* \\ School of Civil Engineering, \\ University of Birmingham, \\ Edgbaston, Birmingham, B15 2TT, UK \\ Email: j.leach@bham.ac.uk \\ *Corresponding author
}

\section{Peter A. Braithwaite}

Birmingham Centre for Resilience Research and Education,

School of Civil Engineering,

University of Birmingham,

Edgbaston, Birmingham, B15 2TT, UK

Email: p.braithwaite@bham.ac.uk

\section{Susan E. Lee, Christopher J. Bouch and Dexter V.L. Hunt}

School of Civil Engineering,

University of Birmingham,

Edgbaston, Birmingham, B15 2TT, UK

Email: s.e.lee@bham.ac.uk

Email: c.bouch@bham.ac.uk

Email: d.hunt@bham.ac.uk

\section{Chris D.F. Rogers}

Birmingham Centre for Resilience Research and Education,

School of Civil Engineering,

University of Birmingham,

Edgbaston, Birmingham, B15 2TT, UK

Email: c.d.f.rogers@bham.ac.uk

\begin{abstract}
The rise in the influence of sustainability principles has resulted in an almost overwhelming number of methods for defining, measuring and assessing sustainability and liveability. For such assessments to be accurate they must have a clearly defined 'sustainability and liveability space', be designed for the context in which the measurements are to be taken, evidence a clear causal chain and make explicit interdependencies. The degree to which current methods meet these criteria is varied. This paper introduces the City Analysis Methodology (CAM), an innovative urban analysis framework for holistically measuring the performance of UK cities with regard to sustainability and liveability. It demonstrates the need for, and defines the
\end{abstract}


parameters for, interventions that enhance rather than compromise wellbeing and provides a model for other countries to leverage the sustainability and liveability of their cities. The paper concludes with an application of the CAM to the design of city infrastructure.

Keywords: liveability; sustainability; urban; cities; city analysis methodology; CAM; city performance; indicators; wellbeing; resources; emissions.

Reference to this paper should be made as follows: Leach, J.M., Braithwaite, P.A., Lee, S.E., Bouch, C.J., Hunt, D.V.L. and Rogers, C.D.F (2016) 'Measuring urban sustainability and liveability performance: the City Analysis Methodology', Int. J. Complexity in Applied Science and Technology, Vol. 1, No. 1, pp.86-106.

Biographical notes: Joanne $M$. Leach has been a researcher on the Engineering and Physical Sciences Research Council- (EPSRC-) funded program grant Liveable Cities since May 2012, which aims to create an holistic, integrated, truly multi-disciplinary city analysis methodology, which uniquely integrates wellbeing indicators, is founded on an evidence base of trials of radical interventions in cities, and delivers realistic and radical engineering solutions. Prior to Liveable Cities, she worked as a project manager on multi-disciplinary research projects in the field of sustainable urban environments. These included VivaCity2020 and Designing Resilient Cities. Her research interests are varied, but have a common focus: sustainable cities. These include understanding and assessing urban sustainability and liveability, futures thinking and designing for future resilience, crime and fear of crime and soundscapes. She is particularly interested in how to facilitate the decision-making processes of local authorities to ensure future resilience along a path of increasing sustainability and liveability.

Peter A Braithwaite has a varied international career in the construction industry and the built environment gaining expertise in sustainability, urban regeneration, geotechnical engineering, mining and environmental services. $\mathrm{He}$ is a former Director at Arup and Head of Sustainability (CH2M HILL) for the London 2012 Olympic Development Agency Delivery Partner, with special responsibility for delivering energy, waste, water, materials, biodiversity and environmental impact sustainability targets. He has a particular interest in developing frameworks, key performance indicators, monitoring and assurance tools for cities and corporate business. He was conferred as Honorary Professor, School of Engineering, University of Birmingham in 2006.

Susan E. Lee is a Research Fellow on the Liveable Cities Project funded by the EPSRC. She has published in a variety of journals including a paper in Nature on climate and vegetation modelling feedbacks in 1997. She has worked within a number of disciplines ranging from architecture, arctic ecology, agriculture, global ecology and meteorology to environmental sciences and engineering. Her research interests are varied, and range from the micro- to the macro-scale effects of both weather and climate on buildings and their occupants as well as vegetation. She is particularly interested in the environmental impact of climate change particularly how this affects the urban environment as well as the natural world.

Christopher $\mathrm{J}$ Bouch is a Chartered Civil Engineer with over 20 years experience in industry with both contractors and consultants. He joined the University of Birmingham at the end of 2003. He currently works on the iBUILD research project, exploring alternative business models for critical local infrastructures; and, the Liveable Cities research project, developing 
alternative approaches to material flow analyses at the urban scale and modelling organised and disorganised complexity. He is particularly interested in systems engineering, complex systems and systems modelling with the application of evaluation and optimisation techniques and has recently been applying these approaches to city systems.

Dexter V.L. Hunt has 13 years experience as a Research Fellow on a portfolio of highly multi-disciplinary research projects focusing upon sustainable and resilient urban infrastructure systems. He is now a Researcher co-Investigator on the Liveable Cities research programme, exploring the urban metabolism and resource flows of cities. He is also a Lecturer within the fields of sustainability and underground construction at the School of Civil Engineering, the University of Birmingham.

Chris D.F. Rogers was appointed to a Chair in Geotechnical Engineering at the University of Birmingham in 1998, where he now leads a number of high-profile research grants. He is the Principal Investigator of the Engineering and Physical Sciences Research Council (EPSRC) funded programme grant Liveable Cities. His research interests include the move towards greater sustainability and liveability in cities, its measurement and use in decision-making, utility service provision, underground space usage, geotechnical processes and urban regeneration as well as exploring future city performance through the use of scenarios.

This paper is a revised and expanded version of a paper entitled 'What makes a city liveable? Implications for next-generation infrastructure services' presented at the ISNGI 2013 Conference, Wollongong, Australia, 1-4 October 2013.

\section{Introduction}

The world is facing considerable challenges around urban sustainability and resilience, and it is widely accepted that there is an imperative to act quickly if serious environmental, social and economic consequences are to be avoided in the future (UK National Ecosystem Assessment, 2011; UN, 2012; WWF, 2014). In our increasingly urban world, cities have an important role to play in achieving sustainability (Rosenzweig et al., 2010; SustainAbility, 2012; UN-HABITAT, 2012; United Nations, Department of Economic and Social Affairs, Population Division, 2014). On the demand-side, the ecological footprint of many cities vastly outstrips their geographic footprint, yet their resource efficiency is greater than many suburban or rural communities. On the supply side, cities are almost entirely dependent upon their hinterlands (and beyond) to supply basic goods and services such as food, water and energy, and to dispose of waste (Calcott and Bull, 2007; Folke et al., 1997; WWF, 2014). Arguments vary as to the influence cities have in creating a more sustainable world, ranging from very little to the only truly effective enabler from the single city perspective, this latter view supporting the idea of cities collectively being the engines of change (Portney, 2013; Vliet, 2002). This paper does not attempt to address this question directly, preferring to acknowledge both the combined influence of cities upon sustainability in the context of rising populations and growing urbanisation and the merit in improving the sustainability of one single city. 
Liveability is almost inextricably linked to the sustainability of cities. In fact, Portney (2013) maintains that, as concepts, liveability and sustainability are practically indistinguishable. In practice, however, a sustainable city is not de-facto liveable and a liveable city is not de-facto sustainable. However it is important to acknowledge that despite, or perhaps because of, extensive writings and reflections on sustainability and liveability, their meanings remain nebulous and open to a myriad of interpretations. This paper proposes that liveability and sustainability can, and should, be inextricably intertwined, incorporating societal and planetary wellbeing within the context of low-carbon living and resource security.

The professionals who shape our cities are educated, trained and practice according to theories and experience derived largely through a single discipline, such as architecture, civil engineering or planning (Cooper et al., 2009; Frey, 1999; Lombardi et al., 2012). This entrenchment in a disciplinary silo, perpetuated by professional qualifications and language, facilitates the analysis, design and implementation of solutions to the complex challenges that cities pose for sustainability and liveability - but only according to the discipline which has driven the analysis. Such limited perspectives will fail to deliver full potential without an overarching framework to address these challenges that also demonstrates the need for, and defines the parameters for, solutions that embrace all relevant disciplinary perspectives (Rogers et al., 2012). The sustainability debate has established that three pillars embrace the core aspects across which the balance should be drawn: economy, society and the environment (Connelly, 2007). Added to this, we know that without social acceptance solutions can be doomed to failure (Assefa and Frostell, 2007; Vallance et al., 2011). A deep understanding of the relationship between wellbeing and behaviour, as it relates to sustainability and city living, is therefore imperative if solutions are to be successful.

Accordingly, Liveable Cities, a five-year, multi-university and highly multi-disciplinary research programme combining around 50 academic researchers with a similar number of practitioner project partners, was established in 2012 to identify and test radical interventions that will lead to sustainable and liveable cities of the future. The specific focus of this programme concerns pathways to low-carbon, resource-secure cities in which societal wellbeing is prioritised, while changes in population, urbanisation, demography, climate, security of energy/other resources, and a plethora of historical legacies, provide the context. The programme focuses upon UK cities, with implications for cities worldwide (see: http://www.liveablecities.org.uk).

This paper introduces the City Analysis Methodology (CAM), which forms a core element of the Liveable Cities programme. The CAM is an urban analysis framework for holistically measuring the performance of a city, demonstrating the need for, and defining the parameters for, the design of city interventions. In order for cities to move towards increased sustainability and liveability, it is important first to understand how cities function and how well they perform. This provides a baseline against which to identify and prioritise aspects that would benefit from change and assess the impact of any proposed interventions. Gaps in performance can then be identified, barriers to achieving a sustainable and liveable future elucidated, and robust interventions designed and assessed. Section 2 of this paper describes how to make operational the measuring of city performance. It begins by describing the rise in prominence of the principles of sustainability and liveability and the concomitant desire to measure them, resulting in an abundance of methods and measures. Section 2.1 discusses the varied definitions of 
sustainability and liveability and defines a measurable 'sustainability and liveability space' for the CAM. In Section 2.2 a framework for measuring city performance derived from the management literature is proposed (the lens framework), and in Section 2.3 the lens framework is applied to the CAM's sustainability and liveability space to form the CAM itself. The discussion section illustrates how the CAM can be used to elucidate causal chains and interdependencies, to design interventions and to assess their impact, with a particular focus upon infrastructure. The paper concludes with a description of future developments for the CAM and applicability to UK cities. It is intended for the CAM to become a methodology, usable by those seeking to create a more sustainable and liveable urban future, and to this end it is being tested by the Liveable Cities team in the UK case study cities of Birmingham, Southampton and Lancaster to explore its robustness in different city contexts.

\section{Measuring city performance: operationalising the concept}

Recent decades have seen a rise in the influence of sustainable development principles. In 1987, the Brundtland Commission published Our Common Future, providing an enduring definition of sustainability and the basis for the Rio de Janeiro Earth Summit in June 1992 (WCED, 1987). The Earth Summit gave rise to Agenda 21, the principles to guide countries towards economic development, including the promotion of sustainable development and a mandate for the United Nations to establish a set of sustainable development indicators (UN, 1993). In 1996 in the UK, Local Agenda 21 was made compulsory via the LA21 policy initiative, placing urban sustainability as a high priority for all levels of UK Government as well as for the private and academic sectors.

As the influence of the principles of sustainability has increased, so has the desire to quantify and measure sustainability itself (Wong, 2006). The result is an abundance of sustainability assessment methods (Bell and Morse, 2008). For example, a UK research programme (sustainable urban environment metrics, models and toolkits for whole life sustainable urban development, SUE MoT) identified more than 600 sustainability assessment methods (McCreadie, 2006), these being categorised as: urban planning tools, design tools, rating systems, life cycle analysis tools and infrastructure. Urban planning tools and rating systems (for buildings) were found to be the most developed. As part of the building environmental quality evaluation for sustainability through time (BEQUEST) project, Deakin et al. (2002) identified more than 100 assessment methods related to sustainable urban development. Gil and Duarte (2013) reviewed tools for evaluating the sustainability of urban design, identifying 35 tools that met their criteria of being at the neighbourhood scale, which assessed sustainability holistically and which were relevant to the early stages of the urban design process. Poveda et al. (2011) pointed to the continued growth in the number of sustainability assessment methods, reiterated the concomitant need for a useful classification system, and identified 12 categories of the most commonly used sustainability assessment methodologies, models, approaches and appraisals. Looking across the methods reveals a multitude of definitions, forms and purposes. It is perhaps not surprising, therefore, that urban designers struggle to be knowledgeable about more than a handful of them (Leach et al., 2014a).

Moreover, whichever assessment method, or combination of methods, is used, the aspirations of citizens, society more generally and those leading cities need to be accounted for. This is a further core element of the Liveable Cities research programme, 
with individual citizen aspirations (Joffe and Elsey, 2014) and societal aspirations being surveyed, while a separate evidence-gathering exercise from those who lead, or are leading thinking in, cities (Rogers et al., 2014) is bringing clarity to the preferred direction of travel. This has been taken forward in policy terms by a UK Government led Foresight Future of Cities project, which explored policy options for the UK's city systems and the UK's system of cities looking forward to 2040 and 2065 (http://www.gov.uk/government/collections/future-of-cities).

For sustainability (and liveability) measurement to be accurate it must have a clearly defined space (Connelly, 2007), be designed for the context in which the measurements are to be taken (Bell and Morse, 2008), evidence a clear causal chain and make explicit interdependencies (Repetti and Desthieux, 2006). The degree to which current methods meet these criteria is varied.

\subsection{Defining the sustainability and liveability space}

Common to all sustainability assessment methods is the concept of sustainability, but this does not mean that the definition of sustainability is the same across the methods. One reason for this is that our understanding of sustainability changes over time (Connelly, 2007; Portney, 2013). Another reason is the contested nature of the term (Bell and Morse, 2008). There is no one, agreed, operational definition of sustainability (Bell and Morse, 2008; Connelly, 2007; Kidd, 1992). The linkage between the environment, society and economy can be seen as a political one not inherent in the concepts themselves. The result is that sustainability assessment methods acknowledge the three-pillar conceptualisation of sustainability and then define an operational space between those pillars that they seek to assess. Each definition is underpinned by a unique set of priorities that when in conflict are resolved in different ways, all under the umbrella of sustainability (Connelly, 2007).

More recently, sustainability assessment is being subsumed into big data, open data and smart city discourses. Information communication technologies (ICT) hold the promise of being able to collect large amounts of data, including real-time data, that will greatly improve our understanding of how cities function. These data are increasingly being brought together either publically, such as on city dashboards available via local authority websites, or privately, such as in data analytics centres (Kitchin, 2014). This emancipation of data is leading to the identification of linkages, interdependencies and points of leverage amongst a much wider set of data and priorities (beyond those traditionally seen as in the domain of sustainability) that up to now have remained elusive and opaque.

Dictionary and thesaurus definitions of liveability indicate that liveability is about being suitable for (usually) human living [Manser et al. (2013), p.605; Merriam-Webster, 2013; Swannell (1986), p.316; The Free Dictionary by Farlex, 2013]. These definitions suggest a basic level of suitability, tolerability and functionality that is at increasing odds with the use of the word when applied to cities. In relation to cities, liveability describes the surpassing of basic living conditions to meet aspirations. This is reflected in the annual rankings of liveable cities by (separately) the Economist's Intelligence Unit, Mercer, and Monocle (Ministry of Foreign Affairs, Denmark, 2013; Parakatil, 2013; The Economist Intelligence Unit, 2013). 
Taking cognisance of these arguments, the CAM defines a 'sustainability and liveability space' within which the performance of a city can be measured, so that baseline performance can be established and the effects of interventions assessed. The space chosen is relevant to urban development and regeneration, and the policies and priorities of UK cities set within their national context. A structured approach adapted from the management literature is adopted to allow for deconstruction and operationalisation.

A review of the academic and practitioner literature on urban development and regeneration as it relates to sustainability and liveability gave rise to three themes:

1 performance

a wellbeing (including community and individual wellbeing)

b resource use (including scarcity, security and efficiency)

c greenhouse gas emissions (including $\mathrm{CO}_{2}$ emissions)

2 context

a built and natural environment

b governance and policy

c economy and finance

d society (including behaviour, social norms and practices)

3 drivers of change

a technology and innovation

b changing populations (including population growth and aging populations)

c peak resources (including energy and food, and competition for resources)

d climate change

e global urbanisation.

The three items grouped under 'performance' underpin the CAM: wellbeing, resources and emissions. These three aspects of performance define the sustainability and liveability space measured by the CAM. The four items grouped under 'context' constitute the context within which the city performs: the city's physical environment, governance structures, economy and social environment. They are included in the CAM as they enable the interpretation of city performance. The five items grouped under 'drivers of change' come into play when designing interventions that will lead to sustainable and liveable cities of the future, and as such fall outside the CAM, but not outside the Liveable Cities research programme.

The application and interpretation of sustainability (and liveability) can only be done in context (Bell and Morse, 2008). The CAM takes the UK as its context, and thus translation of its operation and outcomes to other national contexts requires due consideration. The following describes the CAM's sustainability and liveability space as it relates to the $\mathrm{UK}$.

\subsubsection{Wellbeing}

In 2010 the UK's Prime Minister recognised the need to supplement economic measures of progress by commissioning the Office for National Statistics (ONS) to develop 
measures of 'national wellbeing and progress' [House of Commons Environmental Audit Committee (2012), p.5]. This is one of two recent wellbeing initiatives in the UK, the other being the sustainable development indicators produced by Defra (2013). The Defra indicators measure intergenerational wellbeing (wellbeing across generations) whilst the ONS initiative measures wellbeing within one generation. This two-pronged approach has been criticised by the House of Commons Environmental Audit Committee (2012) as confusing for the public and policymakers. To avoid this confusion the CAM measures both current and intergenerational wellbeing.

The National Health Service Act 1946 (George, 1946) sets out the provision for physical and mental health in the UK as part of a nationalised system. Until recently the NHS sat apart from the services delivered by local councils. This changed with the Health and Social Care Act 2012 (Elizabeth, 2012), which made health the responsibility of local councils. The importance of wellbeing gained prominence in the UK with a Foresight report commissioned by the Government Office for Science on Mental Capital and Wellbeing (Foresight Mental Capital and Wellbeing Project, 2008). This was followed by Marmot et al. (2010), which explored the impacts of social factors on physical and mental wellbeing. Collectively, they reflect that many of the factors that promote wellbeing are, in fact, within the purview of local councils, such as transport, education, housing and planning (Aked et al., 2010). The CAM reflects this thinking and also acknowledges that liveable cities are those that support individual and community wellbeing (Newman, 1999).

\subsubsection{Resources}

In the UK securing the supply of resources is recognised as a national priority and it forms the second underpinning priority for the CAM. 2012 saw the publication of the Resource Security Action Plan (BIS and Defra, 2012). This report recognises that the UK operates within a global system where resource supplies are subject to increasing demand, physical and geopolitical risks. In addition, many of the UK's resources are imported, although it does have indigenous sources of construction and some industrial materials and some capacity to increase local production. This exposes the UK, and UK businesses, to vulnerabilities.

Resource security (ensuring security of supply) must incorporate resource efficiency (efficient use of resources) (Dobbs et al., 2011). For the supply of resources to be truly secure it must be secure over time. As all resources are finite their security over time can only be ensured if their current use does not exceed their ability to regenerate or recycle (acknowledging that some resources cannot regenerate or recycle). Furthermore, the efficiency of resource use must equal or exceed the resource's regeneration/recycle rate if diminished availability is to be avoided in the future. However, it should be noted that this relationship does not necessarily hold in reverse: the efficient use of resources can be achieved with resources that do not have a secure supply chain.

The interactions between resource use, $\mathrm{CO}_{2}$ emissions (see below) and wellbeing gave rise to six categories of resources fundamental to UK city processes and incorporated into the CAM: energy, waste, water, food, carbon-intensive materials and people (in particular, daily commuting and annual migration). Seven carbon-intensive materials were identified: steel; aluminium; cement; plastic; paper (Allwood et al., 2011); glass (of particular relevance to the case study city of Birmingham, UK); and sand, gravel and aggregates (construction materials such as these being heavy, bulky and 
carbon-intensive to transport). The CAM utilises material and energy flow analyses (MEFA) to more fully understand a city's resource security and efficiency (Hunt et al., 2014; Lee et al., 2014).

\subsubsection{Emissions}

The Climate Change Act 2008 [Elizabeth, (2008), p.1] saw passing into law the UK's commitment "to ensure that the net UK carbon account for the year 2050 is at least $80 \%$ lower than the 1990 baseline". Achievement of this target is the third underpinning priority for the CAM. Figures for $\mathrm{CO}_{2}$ emissions for the UK and for UK cities are available, but this measure alone reveals little about how the emissions came about, from where and by whom. If the purpose is to implement interventions to reduce anthropogenic $\mathrm{CO}_{2}$ emissions, it is more useful to consider the activities that contribute to the emissions. These activities can be technological, such as emissions from an industrial process, or behavioural, such as choosing to drive a car with an internal combustion engine or one powered by electricity. The combination of the types of technologies and how they are used gives rise to anthropogenic $\mathrm{CO}_{2}$ emissions (Hunt et al., 2013). The CAM uses the MEFAs previously described as a basis for calculating $\mathrm{CO}_{2}$ emissions, attributing $\mathrm{CO}_{2}$ emissions to each element of a flow to build a picture of the city's emissions related to its resource use (Hunt et al., 2014; Lee et al., 2014).

\subsection{Designing the lens framework}

A lens framework has been established based upon the three pillars of sustainability plus governance. This reflects the UK Government's approach to sustainability as well as drawing in the four contextual priorities identified in the literature review (built and natural environment, governance and policy, economy and finance, and society).

In Securing the Future [Defra, (2005), p.16] the UK Government set out its five pillars of sustainable development. Whilst all UK policies must be underpinned by all five pillars, they do not have to be equally prioritised. Within the pillars, the government recognises the interconnectedness of the three core pillars of sustainability: economic, social and environmental. The five pillars are:

1 living within environmental limits: respecting the limits of the planet's environment, resources and biodiversity - to improve our environment and ensure that the natural resources needed for life are unimpaired and remain so for future generations

2 ensuring a strong, healthy and just society: meeting the diverse needs of all people in existing and future communities, promoting personal wellbeing, social cohesion and inclusion, and creating equal opportunity for all

3 achieving a sustainable economy: building a strong, stable and sustainable economy which provides prosperity and opportunities for all, and in which environmental and social costs fall on those who impose them (polluter pays), and efficient resource use is incentivised 
4 promoting good governance: actively promoting effective, participative systems of governance in all levels of society - engaging people's creativity, energy, and diversity

5 using sound science responsibility: ensuring policy is developed and implemented on the basis of strong scientific evidence, whilst taking into account scientific uncertainty (through the precautionary principle) as well as public attitudes and values.

Whilst the five pillars themselves have remained unchanged since 2005, what has changed is their relative emphasis. In 2005 the Government stated that "We want to achieve our goals of living within environmental limits and a just society, and we will do it by means of a sustainable economy, good governance, and sound science" [Defra (2005), p17]. By 2011 there had been a change in emphasis towards economic growth: "The government has initiated a series of growth reviews to put the UK on a path to a strong, sustainable and balanced growth. Our long term economic growth relies on protecting and enhancing the environmental resources that underpin it, and paying due regard to social needs" [House of Commons Environmental Audit Committee, (2011), p.12]. It is not the purpose of this paper to explore the underpinning reasons for this, but certainly the recent financial crisis has played its part, thus emphasising the role of context in shaping visions and the need for new business models that capture social and environmental value alongside economic value. Coupled with the Government's localism policy, the effect has been an emphasis upon leveraging market forces, bringing with it the concomitant need for financial return and relaxing of sustainability criteria (Tallon, 2013).

Effective urban assessment methods should establish causal chains and interdependencies both between systems and between measures (Repetti and Desthieux, 2006). There is no 'industry standard' method for achieving this within the sustainability and liveability assessment literature (nor, indeed, within the wider urban management literature) (Repetti and Desthieux, 2006). However, there is within the organisational management literature. The classic strategic planning hierarchy is a structured approach to deconstructing and making operational vision statements by linking them to business objectives, strategic goals, success factors, action plans, and finally performance measures (Bititci et al., 1997; Bordum, 2010). $\mathrm{CH}_{2} \mathrm{M}$ HILL used this structure to create their sustainable city framework $\left(\mathrm{CH}_{2} \mathrm{M}\right.$ HILL, 2011).

The lens framework draws upon the strategic planning hierarchy and $\mathrm{CH}_{2} \mathrm{M}$ HILL's Sustainable City Network, adapting them to the UK urban context and the CAM's sustainability space. The result links the CAM's four lenses to a set of goals, which have arising actions and measures (see Figure 1). The lens framework is designed to enhance (rather than compromise) wellbeing, resource security and low-carbon living and to make clear the pathways to impact: each lens has associated goals that are delivered via actions, the impacts of which are measured. In practice, tensions between priorities are inevitable, but by using the lens framework to assess the impact of interventions trade-offs will be made explicit. 
Figure 1 Lens framework (see online version for colours)

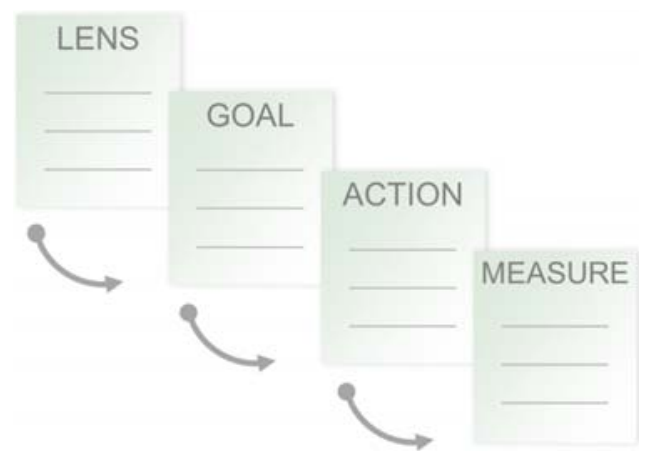

\subsection{The CAM}

Each level of the lens framework was informed by the literature review and UK government priorities, initiatives and policies. In addition, a series of consultation meetings was held with the members of the Liveable Cities academic team who have expertise in wellbeing, urban design, engineering, planning, architecture, social sciences, mobilities, aspirations, energy, water, transport, governance and policy, economics and financing, business models, biodiversity, ecosystem services, urban geography, density and decision-making. The result is a theoretical framework for analysing city performance. Future work includes testing the framework with practitioners and on three UK cities: Birmingham, Lancaster and Southampton.

The first level of the lens framework is the four lenses previously described: society, environment, economy and finance, and governance and policy. Goals form the second level of the framework. Goals disaggregate the lenses into a small number of desired outcomes. Goals are not specific enough to set policies or measure performance. Associated actions are therefore required to provide enhanced detail and desired directions of travel. These actions form the third level of the framework, as illustrated in the following examples.

1 Lens: society

- goal: enhance community and individual wellbeing

a action: promote healthy living and healthy long lives

b action: increase the match between city dweller aspirations and wellbeing

c action: minimise ill-being

d action: maximise social and cultural benefit

- goal: ensure equity (fairness)

a action: ensure an enabling physical environment to maximise individual capabilities in the context of carbon reduction and resource security

b action: ensure an enabling social environment to maximise individual capabilities in the context of carbon reduction and resource security

c action: ensure an enabling economic environment to maximise individual capabilities in the context of carbon reduction and resource security. 
2 Lens: environment

- goal: enhance biodiversity and ecosystem services

a action: minimise the impact of urban density on biodiversity

b action: maximise cultural services (health benefits, recreation, opportunities for outdoor learning)

- goal: ensure resource efficiency

a action: minimise energy use and waste (including heat and $\mathrm{CO}_{2}$ emissions) and maximise energy efficiency

b action: increase the match between wellbeing and minimising high-carbon mobilities while maximising low-carbon mobilities and immobilities of people and objects

c action: minimise potable and non-potable water use and waste (including leakage) and maximise water efficiency

d action: minimise food use and waste and maximise food efficiency

e action: minimise carbon-intensive materials use and waste and maximise their efficiency

f action: minimise other waste produced and maximise its reuse, recycling, repurposing

g action: increase awareness of, and interest in, environmental and climate change issues

- goal: ensure resource security

a action: increase the match between people's aspirations for cities and resource secure cities

b action: increase the match between city dwellers' aspirations and resource secure living

c action: maximise sustainable use of low-carbon local energy first and then maximise the security of supply of non-local energy

d action: maximise sustainable use of local water first and then maximise the security of supply of non-local water

e action: maximise sustainable use of local food first and then maximise the security of supply of non-local food

f action: maximise sustainable use of local carbon-intensive materials first and then maximise the security of supply of non-local carbon-intensive materials

g action: maximise sustainable use of local people first (e.g., utilising the local workforce and leveraging local skills) and then maximise the security of supply of non-local people. 
3 Lens: economy and finance

- goal: maximise sustainable financial investment

a action: maximise investment portfolio structuring designed to support investment with environmental objectives

- goal: ensure economic vitality

a action: uncouple economic vitality from the $\mathrm{CO}_{2}$ emissions associated with economic growth.

4 Lens: governance and policy

- goal: ensure appropriate governance

a action: selection of appropriate governance mechanisms, styles and structures to promote liveability

b action: uncouple governance structures and timescales from political cycles and 'colour' of governing bodies

- goal: ensure appropriate policies

a action: selection and implementation of appropriate policy mechanisms to promote liveability

b action: uncouple policy-making and policy timescales from political cycles and 'colour' of governing bodies.

Achievement of actions is assessed by measuring city performance. The CAM consists of a set of metrics and indicators designed to measure the performance of a city. Metrics can be thought of as those aspects of city performance being measured; e.g., age of usual resident population. Indicators can be thought of as the presentation of the metrics, e.g., mean age of the usual resident population. One metric can be associated with multiple indicators. For example, the metric 'age of usual resident population' is associated with 'mean age of usual resident population', 'median age of usual resident population', 'percentage of the usual resident population that are children', and 'percentage of the usual resident population that are senior citizens'.

Indicators fall into two broad types: contextual and performance. A contextual indicator does not have merit on its own, but provides valuable information for the interpretation of other indicators (for example, number of inhabitants). A performance indicator speaks on its own to the issues being addressed (for example, healthy life expectancy), an adaptation that complements those presented elsewhere (Bell and Morse, 2008; adapted from Mant, 2001; UN, 1993). Indicators frequently give rise to statistics, as they do for Eurostat, the statistical office of the European Union (see http://epp.eurostat.ec.europa.eu/portal/page/portal/eurostat/home/). They are not, however, constrained to numerical representation, as statistics are. Indicators can be qualitative in nature as well as quantitative (Bell and Morse, 2008). Both types of data and both types of indicators are included in the CAM.

A review of the sustainability and liveability measurement literature reveals a number of desirable properties for the CAM's indicators, with two useful additions (numbers 15 and 16): 
1 be simple, elegant and effective (Hardi and Zdan, 1997; Harger and Meyer, 1996; Repetti and Desthieux, 2006; UN, 2001b).

2 holistically address sustainability - and liveability (Hardi and Zdan, 1997; Harger and Meyer, 1996; Maclaren, 1996; UN, 2001a)

3 be measurable, where possible in a standardised way (Hardi and Zdan, 1997; Harger and Meyer, 1996)

4 overlap as little as possible (Harger and Meyer, 1996)

5 be sensitive to change (Harger and Meyer, 1996)

6 be conceptually sound (Bossel, 2001; UN, 2001a)

7 do not compromise underlying complexity (Bossel, 2001; Repetti and Desthieux, 2006; UN, 2001b)

8 be easy to understand, clear and unambiguous (UN, 2001a)

9 be relevant and easy to use in decision-making (Hardi and Zdan, 1997; UN, 2001b)

10 primarily use existing data or data that are easy to obtain in a reasonable timescale and at reasonable cost (UN, 2001a)

11 measure and calibrate progress toward agreed goals in agreed timeframes (Hardi and Zdan, 1997; Harger and Meyer, 1996; House of Commons Environmental Audit Committee, 2012; UN, 2001a)

12 assess trends, incorporating relative and absolute changes (Hardi and Zdan, 1997; Harger and Meyer, 1996)

13 have clear boundaries - noting that varying boundaries to suit the question is beneficial, but requires the context is appropriately set (Bell and Morse, 2008; Bossel, 2001)

14 are organised in a useful way (Bossel, 2001; Hardi and Zdan, 1997)

15 incorporate subjective and objective measures

16 consider all aspects of an issue: consumption and production, demand and supply.

A number of mechanisms have been used to identify the CAM metrics and indicators. This included a top-down approach using the lens framework to identify a causal chain as described above. As this work progressed it was important to allow bottom-up and middle-out associations to be made. Therefore, the metrics and indicators were disassociated from the lens framework, 21 themes were identified and complementary metrics within these themes researched and added where appropriate. Their interpretation is dependent upon the context within which the city performs: its built and natural environment, governance and policies, economy and finance, and society. In order to identify the best contextual measures for the UK a systematic review of the measures gathered by the UK's ONS was conducted. 
Currently the CAM contains 231 metrics giving rise to 288 indicators, although this may change as UK city performance data are gathered and analysed. The resultant set of metrics and indicators, along with their associated actions, goals and lenses comprise the CAM.

\section{Discussions}

Infrastructure systems provide the structures and mechanisms through which cities function at their most basic: supplying energy and water, removing waste, etc. Infrastructure systems also provide the structures and mechanisms though which cities function at their most sophisticated: ICT, integrated public transport, low-carbon energy, re-use and recycling, sustainable communities, etc. Thus infrastructure is crucial in achieving urban sustainability and liveability. The lens framework, on which the CAM is based, elucidates causal chains and interdependencies both between systems and between indicators. This aids decision-makers in understanding the implications of their decisions not only on the desired indicators, but on the system of which the measure is a part and on other systems. For example, the city of Birmingham in the UK is currently extending its light rail (metro) system into the heart of the city. One of the aims is to increase the number of people who take public transport and to reduce the number of people who access the city by private car. Within the CAM the direct impacts of this intervention are measured using the indicators associated with the action: increase the match between wellbeing and minimising high-carbon mobilities while maximising low-carbon mobilities and immobilities of people and objects. Ascending a level (to that of goals) in the CAM hierarchy shows that this intervention affects the greater goal of resource efficiency, which is perhaps obvious. Less obvious is the link between extending the metro and minimising carbon-intensive materials (an action that sits in the same family of actions as increasing the match between wellbeing and minimising high-carbon mobilities...). Reducing car use reduces the demand for cars and with fewer cars manufactured, less steel and aluminium are used in the automotive industry. The goal of ensuring resource efficiency sits within the environment lens alongside enhancing biodiversity and ecosystem services. Enhancing biodiversity and ecosystem services has the related action of maximising cultural services (including health benefits, recreation and opportunities for outdoor learning). With fewer cars in Birmingham, fewer roads and car parks are required and more space can be given over to recreational facilities with concomitant health benefits. In addition, fewer cars mean less pollution, which is also good for health. Health benefits can be measured using the CAM by ascending to the highest level (that of the lens) and drilling down through the goal of enhancing community and individual wellbeing to the action of promoting healthy living and healthy long lives to the associated performance indicators. Figure 2 visually represents these interdependencies.

By navigating the CAM in this way, users are able to decide which relationships apply to a given intervention and context, what the areas of priority are and where performance needs to be measured. In an ideal world with no restrictions upon resources, capacities or capabilities, and no changing context, the full CAM would be used to measure performance before and after any type of intervention. In the real world this simply is not possible and so the CAM elucidates potential interactions and provides related measures of performance. 
Figure 2 Using the lens framework to identify interdependencies

LENS

GOAL

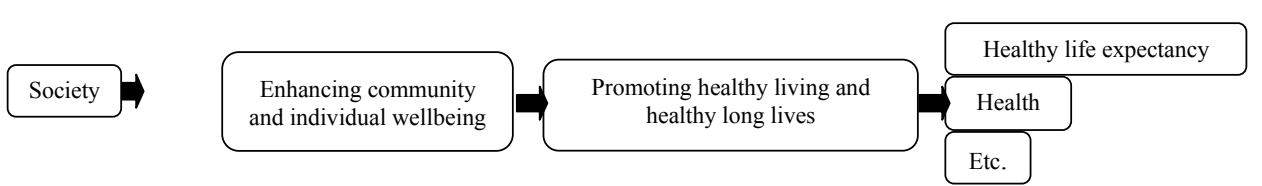

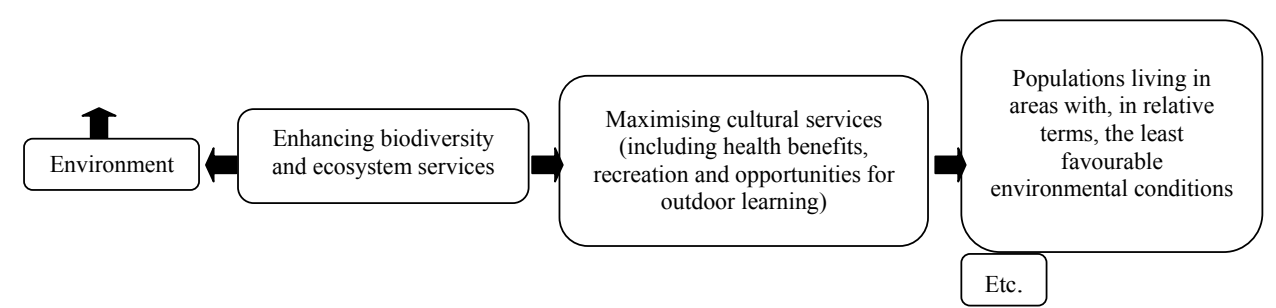

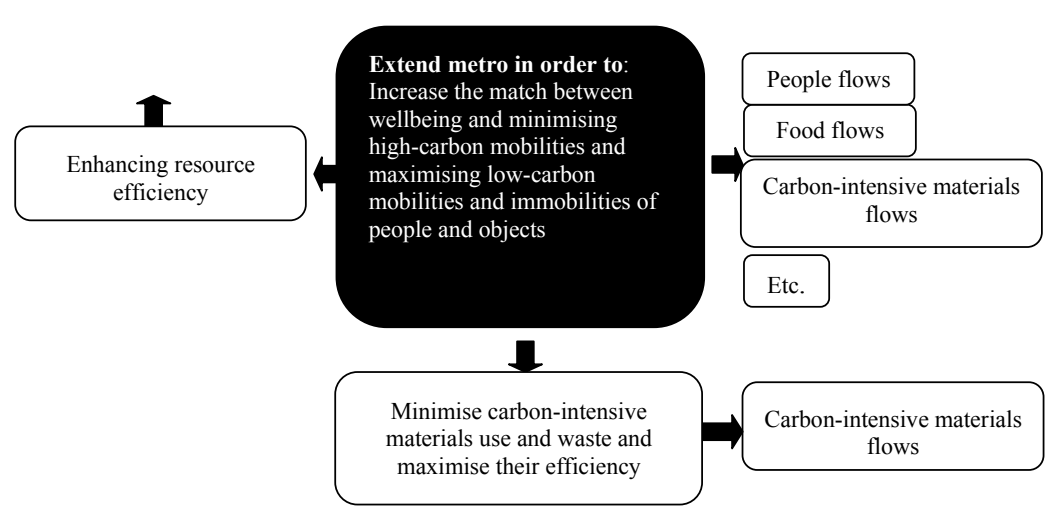

Although knowing the impacts of implementing interventions has value, ameliorating unforeseen or unintended negative impacts once an intervention is in place can be difficult, time consuming and costly (Lombardi et al., 2011). Being aware of negative impacts prior to implementation allows for interventions to be redesigned to minimise negative impacts and maximise positive impacts. To this end the CAM can be used to theoretically assess impacts before implementation. For this, users should consult as many disciplines as possible to ensure different perspectives are considered and a more robust outcome results (Lombardi et al., 2011), and a structured approach to identifying the full range of potential intended benefits of the intervention, and whether the conditions are in place for those benefits to be delivered now and in the future, should be followed [such as the designing resilient cities methodology; see Lombardi et al. (2012)]. In addition, citizens should be empowered within this process to create and deliver their city's narrative - an embellished city vision that incorporates the city's history, current context and future vision (Rogers et al., 2014).

The CAM described herein is a tool to measure the impacts of change. It does not measure progress towards sustainability or liveability (acknowledging that these are not an end state as such, but a direction of travel). To do this two additional aspects will be introduced to the CAM: 
1 setting targets and timescales

2 incorporating relative and absolute changes.

Performance indicators must have targets in order to be meaningful and the targets must have a temporal aspect to them (Harger and Meyer 1996; House of Commons Environmental Audit Committee, 2012; UN 2001; Hardi and Zdan 1997). At its most basic level, a target describes a desired end point and deadline for achieving it. A more nuanced and insightful target acknowledges that not all targets can be achieved using a linear approach and thus incorporates magnitude and speed of change (Leach et al., 2014b). Relative changes in performance are important, but should not be at the exclusion of absolute changes. In some cases, for example, there is a threshold in the economic viability of securing a resource, a tipping point in a natural system, or a point in time where a resource will have been exploited.

Lastly, it is important to reiterate that the CAM is built upon international academic and practitioner literature and practice refined specifically for the UK. Transferability of the framework to other national contexts will require adjustment to the CAM. The results may be variable as different countries have different levels of sustainability and liveability embedded into legislature and guidance - that is they have a different context, reinforcing the observation that what might be effective in moving one city towards a more sustainable and liveable state might not be effective in another city.

\section{Conclusions}

This paper describes the process followed to design and populate a framework for measuring city performance: the CAM. The CAM is used to measure 'as is' city performance. It describes a specified, UK sustainability and liveability space that prioritises wellbeing, resource security and $\mathrm{CO}_{2}$ emissions. It is part of a five-year programme of research, the Liveable Cities programme, set up to identify and test radical interventions that will lead to more sustainable and liveable cities of the future. The CAM provides a baseline of city performance against which to identify and prioritise aspects that would benefit from change and then to assess the impact of any proposed interventions (measuring performance before and after interventions). This allows gaps in performance to be identified, barriers to achieving a more sustainable and liveable future elucidated, and robust interventions to be designed and assessed. The challenge is in attributing changes to implemented interventions in complex city systems where it is impossible to hold all other variables constant. In this respect, by applying the CAM in full before and after an intervention it may only be possible to identify that a significant, broadly positive or negative, change in city performance has occurred - there being changes in several of the CAM's indicators relative to the baseline. This is because other aspects of city performance might well have altered, i.e., the context in which the intervention has been implemented has changed. This means that further work is required to unpick how much can be attributed to the implemented intervention. Nevertheless, what the CAM does offer, once the baseline performance of a city has been established, is the opportunity to hypothesise how an intervention would impact the many indicators. This enables a refinement of the analysis, embedded in the Designing Resilient Cities methodology (Lombardi et al., 2012), to be undertaken: identifying and then embellishing all of the potential intended benefits from the intervention, establishing the conditions 
necessary for those benefits to be delivered, determining whether those conditions are in place (now and in the future), and predicting the consequences (or impacts) of the intervention. As such, it adds a powerful 'enabler' to the suite of tools aimed at practitioners, city leaders and policy-makers who seek to meet the aspirations of their citizens while making their cities more sustainable, resilient and liveable.

\section{Data availability}

The underpinning data for this publication are currently available from the lead author and will be made available in an open access data depository six months after the completion of the Liveable Cities research programme (November 2017), as future papers will draw upon these data.

\section{Acknowledgements}

The authors wish to thank the UK Engineering and Physical Sciences Research Council (EPSRC) for their support under grant number EP/J017698/1. They also gratefully acknowledge the considerable inputs to their thinking provided by the many collaborative researchers at the Universities of Birmingham, Lancaster, Southampton and University College London (UCL), and Liveable Cities' many practitioner project partners who have contributed to six-monthly workshops and shaped the research in many other ways.

\section{References}

Aked, J., Michaelson, J. and Steuer, N. (2010) The Role of Local Government in Promoting Wellbeing, Local Government Improvement and Development, London.

Allwood, J.M., Cullen, J.M., Carruth, M.A., Cooper, D.R., McBrien, M., Milford, R.L., Moynihan, M.C. and Patel, A.C.H. (2011) Sustainable Materials with Both Eyes Open: Future Buildings, Vehicles, Products and Equipment - Made Efficiently and Made with Less New Material, UIT Cambridge, Cambridge.

Assefa, G. and Frostell, B. (2007) 'Social sustainability and social acceptance in technology assessment: a case study of energy technologies', Technology in Society, Vol. 29, No. 1, pp.63-78.

Bell, S. and Morse, S. (2008) Sustainability Indicators: Measuring the Immeasurable?, 2nd ed., Earthscan, London.

Bititci, U.S., Carrie, A.S. and McDevitt, L. (1997) 'Integrated performance measurement systems: a development guide', International Journal of Operations and Production Management, Vol. 17, No. 5, pp.522-534.

Bordum, A. (2010) 'The strategic balance in a change management perspective', Society and Business Review, Vol. 5, No. 3, pp.245-258.

Bossel, H. (2001) 'Assessing viability and sustainability: a systems-based approach for deriving comprehensive indicator sets', Conservation Ecology, Vol. 5, No. 2, p.12.

Business, Innovation and Skills (BIS) and Department for Environment, Food and Rural Affairs (Defra) (2012) Resource Security Action Plan: Making the Most of Valuable Materials, Department for Environment, Food and Rural Affairs (Defra), London.

Calcott, A. and Bull, J. (2007) Ecological footprint of British city residents: what we can do to reduce ours, WWF, Godalming, Surrey, UK. 
$\mathrm{CH}_{2} \mathrm{M}$ HILL (2011) Helping Cities Strategize for a More Sustainable Urban Future. Flyer edn, $\mathrm{CH}_{2} \mathrm{M}$ HILL, Colorado.

Connelly, S. (2007) 'Mapping sustainable development as a contested concept', Local Environment, Vol. 12, No. 3, p.259.

Cooper, R., Evans, G. and Boyko, C. (Eds.) (2009) Designing Sustainable Cities, Wiley-Blackwell, Oxford.

Deakin, M., Huovila, P., Susheel, R. et al. (2002) 'The assessment of sustainable urban development', Building Research and Information, Vol. 30, No. 2, pp.95-108.

Department for Environment, Food and Rural Affairs (Defra) (2005) Securing the Future: Delivering UK Sustainable Development Strategy, The Stationery Office, London.

Department for Environment, Food and Rural Affairs (Defra) (2013) Sustainable Development Indicators July 2013, Department for Environment, Food and Rural Affairs (Defra), London.

Dobbs, R., Oppenheim, J., Thompson, F., Brinkman, M. and Zornes, M. (2011) Resource Revolution: Meeting the World's Energy, Materials, Food and Water Needs [online] http://www.mckinsey.com/insights/energy_resources_materials/resource_revolutionMcKinsey Global Institute (accessed 3 October 2014).

Elizabeth II (2008) Climate Change Act 2008, Act ed., UK, London.

Elizabeth II (2012) Health and Social Care Act 2012, Act ed., UK, London.

Folke, C., Jansson, A., Larsson, J. et al. (1997) 'Ecosystem appropriation by cities', Ambio, Vol. 26, No. 3, pp.167-172.

Foresight Mental Capital and Wellbeing Project (2008) Mental Capital and Wellbeing: Making the Most of Ourselves in the 21st Century, The Government Office for Science, London.

Frey, H. (1999) Designing the City: Towards a more Sustainable Urban Form, Routlege, New York.

George VI (1946) National Health Service Act 1946, Act ed., England and Wales, London.

Gil, J. and Duarte, J.P. (2013) 'Tools for evaluating the sustainability of urban design: a review', Proceedings of the ICE - Urban Design and Planning, Vol. 166, No. 6, pp.311-325.

Hardi, P. and Zdan, T. (Eds.) (1997) Principles in Practice, International Institute for Sustainable Development, Winnipeg.

Harger, J.R.E. and Meyer, F.M. (1996) 'Definition of indicators for environmentally sustainable development', Chemosphere, Vol. 33, No. 9, pp.1749-1775.

House of Commons Environmental Audit Committee (2011) Embedding Sustainable Development: the Government's Response: Fourth Report of Session 2010-12, The Stationary Office, London.

House of Commons Environmental Audit Committee (2012) Measuring Well-Being and Sustainable Development: Sustainable Development Indicators, Fifth Report of Session 2012-13, The Stationery Office Limited, London.

Hunt, D.V.L., Jefferson, I. and Rogers, C.D.F. (2013) 'Scenarios analysis through a futures performance framework', Engineering Sustainability, Vol. 166, No. ES5, pp.258-271.

Hunt, D.V.L., Leach, J.M., Lee, S.E., Bouch, C.J., Braithwaite, P.A. and Rogers, C.D.F. (2014) 'Material flow analysis (MFA) for liveable cities', in The 4th World Susatinability Forum, 1-30 November 2014.

Joffe, H. and Elsey, J. (2014) 'Free association in psychology and the grid elaboration method', Review of General Psychology, Vol. 18, No. 3, pp.173-185.

Kidd, C.V. (1992) 'The evolution of sustainability', Journal of Agricultural and Environmental Ethics, Vol. 5, No. 1, pp.1-26.

Kitchin, R. (2014) 'The real-time city? Big data and smart urbanism', GeoJournal, Vol. 79, No. 1, pp.1-14. 
Leach, J.M., Boyko, C.T., Cooper, R. et al. (2014a) 'Do sustainability measures constrain urban design creativity?', Proceedings of the ICE - Urban Design and Planning, Vol. 168, No. DP1, pp.30-41.

Leach, J.M., Lee, S.E., Braithwaite, P.A., Bouch, C.J., Grayson, N. and Rogers, C.D.F. (2014b) 'What makes a city liveable? Implications for next-generation infrastructure services' in Infrastructue for a Better Future: a Forum for Vision, Leadership and Action, 1-4 October 2013, The SMART Infrastructure Facility, University of Wollongong, Australia, p.397.

Lee, S.E., Leach, J.M., Hunt, D.V.L. and Rogers, C.D.F. (2014) Material Flow Analysis: Outcome Focus (MFA:OF) for Elucidating the Role of Infrastructure in the Development of a Liveable City, in Dolan, T. and Collins, B. (Eds.), 'ISNGI 2014 Presenters' Papers' (2015) UCL, London [online] http://discovery.ucl.ac.uk/1469416/1/Final\%20Proceedings.pdf (accessed 3 October 2014).

Lombardi, D.R., Leach, J.M. and Rogers, C.D.F. (2012) Designing Resilient Cities: a Guide to Good Practice, IHS BRE Press, Watford.

Lombardi, R.D., Caserio, M., Donovan, R. et al. (2011) 'Elucidating sustainability sequencing, tensions, and trade-offs in development decision making', Environment and Planning B: Planning and Design, Vol. 38, No. 6, pp.1105-1121.

Maclaren, V.W. (1996) 'Urban sustainability reporting', Journal of the American Planning Association, Vol. 62, No. 2, pp.184-202.

Manser, M., O'Neill, M. and O'Donoghue, E. (Eds.) (2013) The Chambers Thesaurus, Chambers Harrap Publishers Ltd, Edinburgh.

Mant, J. (2001) 'Process versus outcome indicators in the assessment of quality of health care', International Journal for Quality in Health Care, Vol. 13, No. 6, pp.475-480.

Marmot, M., Allen, J., Goldblatt, P., Boyce, T., McNeish, D., Grady, M. and Geddes, I. (2010) Fair Society, Healthy Lives, The Marmot Review, London.

McCreadie, M. (2006) Client Report: BRE Subcontract: Assessment of Sustainability Tools, Report Number 15961, BRE, Watford.

Merriam-Webster, I. (2013) Liveability [online] http://www.merriam-webster.com/dictionary/ liveability (accessed 20 June 2013).

Ministry of Foreign Affairs, Denmark (2013) Monocle: Copenhagen is the Most Livable City in the World [online] http://www.investindk.com/News-and-events/News/2013/Copenhagen-is-theMost-Livable-City-in-the-World (accessed 13 August 2013).

Newman, P.W.G. (1999) 'Sustainability and cities: extending the metabolism model', Landscape and Urban Planning, Vol. 44, No. 4, pp.219-226.

Parakatil, S. (2013) Defining 'Quality of Living' [online] http://web.archive.org/web/ 20110705043507/ and http://www.mercer.com/referencecontent.htm?idContent=1380465 (accessed 8 July 2013).

Portney, K.E. (2013) Taking Sustainable Cities Seriously: Economic Development, the Environment, and Quality of Life in American Cities (American and Comparative Environmental Policy Series), 2nd ed., MIT Press Boston, Massachusetts.

Poveda, C.A. and Lipsett, M.G. (2011) 'A review of sustainability assessment and sustainability/environmental rating systems and credit weighting tools', Journal of Sustainable Development, Vol. 4, No. 6, pp.36-55.

Repetti, A. and Desthieux, G. (2006) 'A relational indicatorset model for urban land-use planning and management: methodological approach and application in two case studies', Landscape and Urban Planning, Vol. 77, No. 1-2, pp.196-215.

Rogers, C.D.F., Lombardi, D.R., Leach, J.M. et al. (2012) 'The urban futures methodology applied to urban regeneration', Engineering Sustainability, Vol. 165, No. ES1, pp.5-20. 
Rogers, C.D.F., Shipley, J., Blythe, P., Braithwaite, P.A., Brown, C., Collins, B.S., Juned, S., MacKenzie, R.A., Miller, R., Pawlyn, M., Price, J., Swain, C., Tight, M.R., Tindale, S., Toyne, P. and Leach, J.M. (2014) Future Urban Living - A Policy Commission Investigating the Most Appropriate Means for Accommodating Changing Populations and Their Needs in the Cities of the Future, University of Birmingham, Birmingham, UK.

Rosenzweig, C., Solecki, W., Hammer, S.A. et al. (2010) 'Cities lead the way in climate-change action', Nature, Vol. 467, No. 7318, pp.909-911.

SustainAbility (2012) Citystates: How Cities are Vital to the Future of Sustainability, SustainAbility, London.

Swannell, J. (Ed.) (1986) The Little Oxford Dictionary, 6th Clarendon Press, Oxford.

Tallon, A. (2013) Urban Regeneration in the UK, 2nd ed., Routlege, London.

The Economist Intelligence Unit (2013) The Liveability Ranking and Overview August 2012 [online] https://www.eiu.com/public/topical_report.aspx?campaignid=Liveability2012 (accessed 8 July 2013).

The Free Dictionary by Farlex (2013) Liveable [online] http://www.thefreedictionary.com/liveable (accessed 20 June 2013).

UK National Ecosystem Assessment (2011) The UK National Ecosystem Assessment: Synthesis of the Key Findings, UNEP-WCMC, Cambridge.

UN-HABITAT (2012) State of the World's Cities 2012/2013: Prosperity of Cities, World Urban Forum Edition, UN-HABITAT, Kenya.

United Nations (UN) (1993) Agenda 21: The United Nations Programme of Action from Rio, United Nations, New York.

United Nations (UN) (2001a) Indicators of Sustainable Development: Guidelines and Methodologies, E 01 II A 6United Nations, New York.

United Nations (UN) (2001b) Report on the Aggregation of Indicators of Sustainable Development, United Nations, New York.

United Nations (UN) (2012) Report of the United Nations Conference on Sustainable Development, A/CONF.216/16United Nations, New York.

United Nations, Department of Economic and Social Affairs, Population Division (2014) World Urbanization Prospects: The 2014 Revision, Highlights, ST/ESA/SER.A/352United Nations, New York.

Vallance, S., Perkins, H.C. and Dixon, J.E. (2011) 'What is social sustainability? A clarification of concepts', Geoforum, Vol. 42, No. 3, pp.342-348.

Vliet, W.v. (2002) 'Cities in a globalizing world: from engines of growth to agents of change', Environment and Urbanization, Vol. 14, No. 1, pp.31-40.

WCED (1987) Our Common Future: Report of the World Commission on Environment and Development, A/42/427United Nations, New York.

Wong, C. (2006) Indicators for Urban and Regional Planning, Routledge, London.

WWF (2014) Living Planet Report 2014: Species and Spaces, People and Places, WWF, Gland, Switzerland. 